\title{
A Cross-Cultural Comparative Study of Apology Strategies Employed by Iranian EFL Learners and English Native Speakers
}

\author{
Elham Abedi (Corresponding author) \\ English Department, Faculty of Humanities, Najafabad Branch, Islamic Azad University, Najafabad, Isfahan, Iran \\ E-mail: elham.abedi@hotmail.com
}

Doi:10.7575/aiac.alls.v.7n.5p.35

URL: http://dx.doi.org/10.7575/aiac.alls.v.7n.5p.35
Received: 04/05/2016

Accepted: 09/07/2016

\begin{abstract}
The development of speech-act theory has provided the hearers with a better understanding of what speakers intend to perform in the act of communication. One type of speech act is apologizing. When an action or utterance has resulted in an offense, the offender needs to apologize. In the present study, an attempt was made to compare the apology strategies employed by Iranian EFL learners and those of English native speakers in order to find out the possible differences and similarities. To this end, a discourse completion test (DCT) was given to 100 male and female Iranian EFL learners and English native speakers. The respondents were supposed to complete the DCTs based on nine situations, which varied in terms of power between the interlocutors and level of imposition. This study employed Cohen and Olshtain's (1981) model to classify various types of apology strategies. The obtained results revealed some similarities along with some (statistically insignificant) differences between EFL learners and American English speakers in terms of their use of apology strategies. Furthermore, it was found that the illocutionary force indicating devices (IFIDs), such as request for forgiveness and an offer of apology were the strategies mostly employed by the Iranian EFL learners while taking on responsibility such as explicit self-blame, and expression of self-deficiency were found to be the strategies mostly used by English native speakers. In terms of gender, the male and female respondents more or less used the same apology strategies in response to the situations. The findings of the present research can be used by language teachers as well as sociolinguists.
\end{abstract}

Keywords: Speech act theory, Speech act of apology, Apology strategies, Iranian EFL learners, English Native speakers, Gender

\section{Introduction}

In communicative events, there is a need to use language appropriately in different situations. The importance of communication both among English native speakers and among EFL learners has caused linguists to study the pragmatic rules. Investigation of problems of communication among different cultures and cross-cultural pragmatics has attracted a lot of attention. Saville-Troike (1982) stated that communicative competence is regarded as whatever knowledge a speaker needs to know so that s/he can properly communicate while being in a specific speech community. Pragmatic competence has some related concepts like speech acts. Speech acts are one of the key areas of linguistic pragmatics. Language can be used to do some actions, these actions are called speech acts. Specific speech acts include apology, complaint, compliment, refusal, request, and suggestion. Austin (1962) states that speech acts are functions which are done by words like apology and invitation.

\subsection{Statement of the Problem}

One of the common speech acts is the speech act of apology. Apology has been the topic of many studies. People in society need to be able to apologize for an unacceptable behavior. According to Eslami-Rasekh and Mardani (2010) the speech act of apology is used when the partners exceed the social norms. When an impolite behavior or offense occurs the one who has exceeded the social norms should apologize. The concept of apology or other speech acts may differ from culture to culture. People from different cultures respond to different speech acts in different ways. For example, speakers of a particular language (e.g. English) may accept compliments without showing modesty (Rizk, 2003). In such cases a speaker might accept a compliment such as 'You did a really good job' with a simple expression of 'Thanks', that is without expressing any idea about the importance of the compliment. Considering the same speech act in our Iran, native speakers of Persian usually accept compliments, but are culturally expected to show their humbleness.

Due to L1 interference it is possible that Iranian EFL learners respond to compliments in English in the same way as in their mother tongue (the Persian). For example, they might respond to the compliment 'You did a really good job' with an expression of modesty (e.g. Nazare Lutfetune. [Trans.: It's very kind of you]). In this case, it can be said that EFL learners have transferred some pragmatic rules and knowledge of their mother tongue to their foreign language. 
Differently stated, in Persian people usually pretend to be modest in cases when someone compliments them, while in English people usually accept or agree with the compliment. As a result, an English native speaker in this situation may utter 'You're right'.

Pragmatic failure in communication has attracted the attention of a broad spectrum of researchers. Sometimes Iranian EFL learners may fail to communicative effectively due to misunderstanding people from other cultures. Therefore, studies of apology should be extended to capture the whole picture. Concerning teaching English in Iran, most of language programs at university and even prior to that focus on grammar and reading. In real-life situations, hence, Iranian EFL learners may often fail to communicate effectively with foreigners.

\subsection{Purpose of the Study}

It seems that there is not enough research exploring the speech act of apology as used by English native and Persian speakers. Therefore, in line with the body of research in the arena of speech acts, and to fill the existing gap, the present study was conducted. In fact, this study was a multifaceted. First, it was intended to find out the apology strategies employed by English native speakers. In addition, this research was set out to investigate what apology strategies are used by English native speakers. Furthermore, this study intended to compare the Iranian EFL learners and English native speakers' use of apology strategies.

\subsection{Significance of the Study}

Using language in real situations has always been challenging task for many EFL learners in Iran; therefore, the findings of this study can be of significance to EFL learners and teachers. As this study reveals some differences between Iranian English speakers and English native speakers in using the speech act of apology, the results have some implications for the study of cross-cultural pragmatics. First, it should be taken into consideration that certain features of speech acts are essential to in dealing with the cross-cultural differences in using speech acts. Second, the educational importance of comparing apology strategies in different cultures with various linguistic backgrounds is shown. Third, a more comprehensive view of using apology by Iranian and English native speakers is gained through using discourse completion tests (DCT) as a data collection tool. Finally, it can be concluded that pragmatic knowledge is an inseparable part of language. In future materials for teaching the speech acts like apology which have pedagogical implications should be included. The process of communication with English native speakers needs pragmatic awareness, and the results of the present study can help in this way. Including some exercises on real and authentic situations may improve the teaching process of speech acts. Furthermore, syllabus designers can take advantage of the results and try to integrate instances of real language use into the curriculum while designing books and educational materials for speaking courses. Pragmatic features of language should be focused on, as pragmatic awareness can assist teachers and educators. Accordingly, this study intended to answer the following research questions:

RQ1: What types of apology strategies are usually employed by English native speakers?

RQ2: How do Iranian EFL learners and English native speakers vary in terms of using apology strategies?

\section{Literature Review}

The speech act of apology has so far been the topic of various studies in different languages. In the following section, a glance is taken at the existing literature. Savina (2002), in her study on native speakers of Russian living in the United States, showed that the strategies speakers choose to apologize in their native language are also influenced by the target language and culture. The most conclusive example the author gave to illustrate these findings was the incorporation by the Russian native speakers of 'sorry' as an apology for accidentally touching someone. This is, according to her, clearly a result of cultural transfer; as such a situation does not require an apology in the Russian culture. In a study among Iranian EFL learners, Eslamirasekh and Mardani (2010) studied if teaching the speech act of apology affects pragmatic knowledge of EFL Learners. In order to find answer to this research question, Sixty EFL learners were divided into two groups, then the speech act of apology was taught to the participants in experimental group. It was found that explicit teaching of apology speech act leads to better outcomes. Furthermore, the frequency of intensifiers in using apology strategies exchanges was compared as used by Iranian EFL learners and English native speakers, and it was shown that that explicit apology strategy instruction results in more appropriate use of apology instruction.

In another study, Farashaiyan and Amirkhiz (2011) compared the apology strategies used by Iranian EFL and Malaysian ESL students. The researchers used a discourse completion test (DCT) to collect data. The sample of the study included 15 Iranian and 15 Malaysian students. The results indicated that Iranian and Malaysian learners used some different and similar apology strategies. Iranians used 15 apology strategies out of seventeen strategies, while Malaysians used eleven types of apology strategies. Yet in another study Parsa (2012) studied apology and nonapology strategies among Iranian EFL learners based on Cohen and Olshtain's (1981) framework. It was observed that there was significant difference between male and female subjects in using apology and non-apology strategies. However, no statistically significant difference was seen between the groups in terms of the number and type of strategies used.

In a similar study, Salehi (2014) compared the apology strategies used by Iranian EFL learners and English native speakers in different situations descriptively to investigate similarities and differences among them. A discourse completion task (DCT) was run among 21 Iranian MA students and it was also sent to 15 English native speakers through email. The some similarities and few differences were observed in terms of the frequency and the type of strategies. 
Furthermore, Simin, Eslami, Eslami-Rasekh and Ketabi (2014) investigated the possible impacts of explicit instruction of apology speech act through e-mails on mastering of this strategy among Iranian EFL learners. The participants were divided into two groups: the explicit teaching group and the implicit teaching group. Different situations of apology strategies were given to the participants and the experimental group was asked to communicate with the instructor through email. The results of a post test showed that the participants in the first group who experienced email exchanges mastered the apology strategies better than the other group. It was then concluded that explicit instruction of apology strategies when accompanied with e-mail leads to pragmatic awareness.

Last but not least, Nasiri and Forutan (2015) studied the level to which Iranian EFL teachers could employ apology strategies as one specific speech act. In addition, the speech act of apology was evaluated in the course books. The needed data were gathered using a DCT. Significant differences between the public school and institute teachers in terms of apology strategies were observed. A significant difference between the course books used by the institutes and public education system was also observed in terms of apology strategies. The discussion presented in the previous sections highlight the pedagogical importance of this topic. After reviewing the literature, it is clear that there is a lack of research on apology by Iranian EFL learners.

\section{Methodology}

In this section the details about the participants of the study, the used instruments along with data gathering procedures are presented.

\subsection{Participants}

This study recruited 100 participants living in Iran and the United States of America. Participants were organized into two groups: a group of 50 English native speakers, both males and females, whose ages ranged from twenty to fortyfive years. Most of them were undergraduate students involved in different majors at the University of Colorado, USA. Also a group of 50 Iranian EFL learners (25 male, 25 female) both graduate and undergraduate students enrolled in different programs at Islamic Azad University, Najafabad Branch participated in this study. None of the participants in this group had the experience of living abroad.

\subsection{Instruments}

This study made use of a discourse completion test (DCT). The DCT used in this study was adopted from Blum-Kulka (1980) and it was used by Al Ali (2012) in his thesis. This DCT is a written questionnaire that consists of nine designed situations used to elicit specific speech acts. In this study, the DCT representing different social contexts to gather data on different strategies of apology was used. In order to prevent any misunderstanding and confusion the DCT was translated into Persian for Iranian EFL learners. Some changes were provided to the DCT to match it with the Persian context. This test was proofread by an expert to ensure its validity. In addition, Cohen and Olshtain's (1981) model of apology was used for classification of different types of apology strategies used by EFL learners and English native speakers. Cohen and Olshtain (1981) categorized apology strategies as follows:

1. An illocutionary force indicating device (IFID)

- An expression of regret, e.g. I'm sorry

- An offer of apology, e.g. I apologize.

- A request for forgiveness, e.g. excuse me/ forgive me/ pardon me.

2. Explanation or account, e.g. there was a heavy traffic.

3. Taking on responsibility:

- Explicit self-blame, e.g. it's my mistake.

- Lack of intent, e.g. I didn't do it on purpose.

- Expression of self-deficiency, e.g. I totally forgot it.

- Expression of embarrassment, e.g. I feel ashamed.

- Self-castigation, e.g. It was very stupid of me.

- Justify the hearer, e.g. you are right to be angry and disappointed now.

4. An offer of repair, e.g. I'll pay for the damage.

5. Promise of forbearance, e.g. it won't happen again.

\subsection{Data Collection}

The participants were provided with information about the study. They were also assured about the confidentiality of their responses. In order to prevent any misunderstanding, the data collection instruments were provided in both English and Persian. The data from Iranian EFL learners were gathered from the Iranian EFL learners by the researcher. As the discourse completion test consisted of nine situations, the participants were given a time period of one hour for completing the DCT. In order to analyze the gathered data, descriptive and inferential statistics like frequency, percentage and chi-square were used.

\section{Results}

The following section is devoted to the results of the analysis of the DCT for the first research question, which investigated the apology strategies used by English native speakers. 


\begin{tabular}{|c|c|c|c|c|c|}
\hline $\mathrm{N} / \mathrm{F}$ & $\mathrm{N} / \mathrm{M}$ & $\mathrm{N} / \mathrm{F}$ & $\mathrm{N} / \mathrm{M}$ & Frequency & Percentage \\
\hline 133 & 127 & 22.24 & 21.23 & 260 & 43.47 \\
\hline 27 & 26 & 4.51 & 4.34 & 53 & 8.85 \\
\hline 0 & 43 & 0 & 7.19 & 43 & 7.19 \\
\hline 44 & 50 & 7.35 & 8.38 & 94 & 15.73 \\
\hline --- & --- & --- & --- & & \\
\hline 14 & 4 & 2.34 & .66 & 18 & 3 \\
\hline 9 & 2 & 1.50 & .33 & 11 & 1.83 \\
\hline 0 & 0 & 0 & 0 & 0 & 0 \\
\hline 0 & 0 & 0 & 0 & 0 & 0 \\
\hline 5 & 3 & .83 & .50 & 8 & 1.33 \\
\hline 2 & 0 & .33 & 0 & 2 & .33 \\
\hline 2 & 3 & .33 & .50 & 5 & .83 \\
\hline 4 & 1 & .66 & .16 & 5 & .83 \\
\hline 55 & 76 & 9.19 & 12.70 & 131 & 21.89 \\
\hline 3 & 1 & .50 & .16 & 4 & .66 \\
\hline 298 & 300 & 49.84 & 50.16 & 598 & 100 \\
\hline
\end{tabular}

a. An expression of regret.

b. An offer of apology.

c. A request for forgiveness.

(2) Explanation or account:

(3) Taking on responsibility:

a. Explicit self-blame.

b. Lack of intent.

c. Expression of self-deficiency.

d. Expression of embarrassment.

e. Admission of facts but not responsibility.

f. Justify hearer.

g. Refusal to acknowledge guilt: -Denial of responsibility. Blame the hearer. Pretend to be offended.

(4) Concern for the hearer.

(5) Offer of repair.

(6) Promise of forbearance.

Total

$298 \quad 300$

Note: N/F: English native speakers female- N/M: English native speakers male

The first class of apology strategies, namely IFIDs, which is divided into three categories comprised the main portion of the apology strategies employed by male and female English native speakers. In fact $160(26.76 \%)$ out of 598 used apology strategies of the whole apology strategies were employed by female english English speakers. Among the 598 used strategies for apology, 196 (32.76\%) were employed by male English native speakers. In sum, 59.51\% of the strategies was found to be expressed using the three categories of IFIDs.

Among the three classes of apology strategies belonging to the super category of IFIDs, the first group, namely, an expression of regret comprised the highest percentage of the used strategies $(43.47 \%)$. As a case in the point, the phrase I'm sorry was found to be the most highly used strategy by English native speakers. An offer of apology, formed $8.85 \%$ of the elicited strategies. An example of this class of strategies is the sentence I apologize. The last category of apology strategies, A request for forgiveness, comprised $7.19 \%$ of the apology strategies. The next group of apology strategies was the class Explanation or account which was used in $15.57 \%$ of situation by English native speakers. It seems that male and female English native speakers used this strategy at roughly the same proportion, with females making use of this strategy in $7.35 \%$ and males in $8.38 \%$ of situations. The next class of apology strategies according to Cohen and Olshtain's (1981) model is Taking on responsibility, which is a super category comprising seven subcategories. Although this class of apology strategies has the highest number of items, it was found that only in $7.32 \%$ of situations (44 out of 598 strategies) the participants made use of this class.

The next category of the super-category Taking on responsibility is Lack of intent, which was used in 11 situations $(1.83 \%)$ of the whole situations. The other subcategories were used with a percentage of less than $2 \%$. The last group of apology strategies of this class was termed Refusal to acknowledge guilt: -Denial of responsibility, -Blame the hearer, Pretend to be offended. Only in .83\% of the situations was this class of strategies used. Offer of repair, which is the next class of apology strategies, was used more than some other previous strategies. In $21.89 \%$ of the situations, this strategy was used. An example of this class in the obtained data was I'll pay for the damage. The last class of the used apology strategies was Promise of forbearance, which was used in a very low number by the English native speakers (.66\%). 
The next question of this study intended to investigate if Iranian EFL learners used different strategies from English native speakers when apologizing. The results are presented in Table 2. The following section is devoted to the explanations in this regard.

Table 2. Comparison between the Strategies Used by English Native and Iranian EFL learners

\begin{tabular}{|c|c|c|c|c|}
\hline \multirow{2}{*}{$\begin{array}{l}\text { Strategy } \\
\text { (1) Illocutionary force indicating devices (IFIDs), }\end{array}$} & \multicolumn{2}{|c|}{ EFL learners } & \multicolumn{2}{|l|}{ Native } \\
\hline & $\mathrm{NN} / \mathrm{F}$ & $\mathrm{NN} / \mathrm{M}$ & $\mathrm{N} / \mathrm{F}$ & $\mathrm{N} / \mathrm{M}$ \\
\hline a. An expression of regret. & 21.60 & 23.16 & 22.24 & 21.23 \\
\hline b. An offer of apology. & 5.12 & 3.11 & 4.51 & 4.34 \\
\hline c. A request for forgiveness. & 6.90 & 5.79 & 0 & 7.19 \\
\hline (2) Explanation or account: & 8.68 & 7.34 & 7.35 & 8.38 \\
\hline (3) Taking on responsibility: & --- & --- & --- & --- \\
\hline a. Explicit self-blame. & 0 & 0 & 2.34 & .66 \\
\hline b. Lack of intent. & .22 & 0 & 1.50 & .33 \\
\hline c. Expression of self-deficiency. & 0 & 0 & 0 & 0 \\
\hline d. Expression of embarrassment. & .66 & .22 & 0 & 0 \\
\hline e. Admission of facts but not responsibility. & .22 & 0 & .83 & .50 \\
\hline f. Justify hearer. & .22 & .66 & .33 & 0 \\
\hline $\begin{array}{l}\text { g. Refusal to acknowledge guilt: -Denial of } \\
\text { responsibility. -Blame the hearer. Pretend to be } \\
\text { offended. }\end{array}$ & .22 & 0 & .33 & .50 \\
\hline (4) Concern for the hearer. & 0 & 0 & .66 & .16 \\
\hline (5) Offer of repair. & 7.57 & 7.57 & 9.19 & 12.70 \\
\hline (6) Promise of forbearance. & 0 & .22 & .50 & .16 \\
\hline Total & 50.97 & 49.03 & 22.24 & 21.23 \\
\hline
\end{tabular}

In terms of quantity, the total number of apology strategies used by Iranian EFL learners was 449, while English native speakers used 598 apology strategies, that is a difference of 149 strategies. The total number of IFIDs was found to be 295 for Iranian EFL learners and 356 for English native speakers. The first type of apology strategies Expression of regret comprised $43.47 \%$ of the whole used strategies used by English native speakers, while $44.76 \%$ of Iranian EFL learners made use of this class of strategies.

Offering an apology was used in $8.85 \%$ of situations by English native speakers and in $8.23 \%$ of situations by EFL learners. A request for forgiveness was used in $12.69 \%$ of the situation by Iranian EFL learners and in $7.19 \%$ of the situations by English native speakers. Explanation or account comprised 16.02\% of Iranian EFL learners' apology strategies and $15.73 \%$ of English native speakers' apology strategies. The next class, Explicit self-blame, was used with a percentage of 3\% by English native speakers, while Iranian EFL learners did not use this class at all. 'Lack of intent' was used in $.22 \%$ situations by Iranian EFL learners; however, $1.83 \%$ of Iranian EFL learners made use of this strategy.

Expression of self-deficiency was not used by the English native speakers and Iranian EFL learners at all. Expression of embarrassment was used in $88 \%$ of situations. As the next class of apology strategies Admission of facts but not responsibility was used in .22\% of situations by Iranian EFL learners and in $1.33 \%$ of cases by English native speakers. Around $.88 \%$ of Iranian EFL learners stated that they justified the offended for apologizing, while only .33\% of English native speakers used this class of apology strategies. Refusal to acknowledge guilt: (Denial of responsibility, Blame the hearer, and Pretend to be offended) was the next class of strategies which was used by .22\% of Iranian EFL learners and by $.83 \%$ of English native speakers.

Concern for the hearer was the next class used by .82\% of English native speakers and it was not used by any of Iranian EFL learners. Offer of repair was used in $15.14 \%$ of situations by Iranian EFL learners and in $21.89 \%$ situations by English native speakers. Promise of forbearance was used in $.22 \%$ of situations by EFL learners and in $.66 \%$ of situations by English native speakers. 
In order to find out if there was any significant difference between English native speakers and EFL learners in terms of their employment of apology strategies, a chi-square test was run between different classes of apology strategies used by English native speakers and EFL learners. The obtained results are presented in Table 3.

Table 3. The Results of Chi-Square Test between English Native Speakers and EFL Learners in Their Apology Strategies

\begin{tabular}{llll} 
& Value & Df & Asymp. Sig. (2-sided) \\
\hline Pearson Chi-Square & $20.533 \mathrm{a}$ & 17 & .248 \\
Likelihood Ratio & 28.267 & 17 & .042 \\
N of Valid Cases & 28 & & \\
\hline
\end{tabular}

According to the statistics presented in Table $4, \chi(17)=20.53, p=.248$. This tells us that there is no statistically significant difference between EFL learners and English native speakers in terms of their use of apology strategies.

As it was stated earlier, the participants of this research were asked to respond to nine imaginary situations. What follows is the detailed explanation of obtained responses in terms of the gender of the participants.

Situation 1: Imagine that you are teaching at a university. It's morning and the head of your department has held a meeting now with a number of professors along with you. You don't know the head of the department well. He was noting something that you unintentionally interrupt him. She says angrily: 'I wasn't done. Please don't interrupt me.' What would you say?

In response to this situation, the first class of illocutionary force indicating devices (IFIDs), namely, expression of regret was utilized more than other devices by the participants. However, among the participants, the EFL learners made use of this strategy of apology less than others (12\%), and EFL male respondents applied this strategy more than others $(25.5 \%)$. Offering an apology was the next class of apology strategies used mainly by the respondents. However, more or less the participants made use of it at the same range. It should be said that male English native speakers chose this item more than others (28\%). A request for forgiveness was surprisingly used in the same range by Iranian male and female speakers (13.45\%). Explanation or account was used only by $4 \%$ by male English native speakers and $8.56 \%$, by EFL male learners. EFL female learners used this strategy just in two cases, while EFL male learners did not report to use this strategy. I had an important appointment was a case in this point. The other strategies were not used by English native speakers and EFL learners, and also by female EFL learners; however, in 4\% of situations, female English native speakers used the strategy of lack of intent like I didn't mean to interrupt you. Three other items, namely, expression of self-deficiency, justify hearer and admission of facts but not responsibility (e.g. You can study at library.) were used only in 3\% of situations each by female English native speakers.

Situation 2: Imagine that you are a teacher at a school and you are at the manager's office in order to have him sign some papers. You don't talk to the secretary, she tells you that the manager is not in, while putting the papers on secretary's desk, you spill the orange juice all over her skirt. She says: "Oh, my goodness!" What would you say?

Expression of regret was used more than other strategies by both male and female English native speakers; however, male EFL learners made use of this strategy less than female EFL learners. Offering an apology was also used just rarely. For example, female English native speakers made use of this strategy only with a percentage of $2 \%$ (I apologize). In total, this strategy was used by the participants only by $33 \%$. Request for forgiveness was only used by EFL learners, and English native speakers made no use of this strategy. Among EFL learners, males used this strategy more than females. Other strategies like explanation or account were used just in one case by male English native speakers and EFL learners, and also just in one case by female English native speakers. The female EFL learners used this strategy only by $4 \%$. The only striking difference of these strategies was offer of repair, which was used by $47 \%$ by male English native speakers and $34 \%$ by female English native speakers; however, EFL learners used this strategy only by $13 \%$. In the scenario stated in situation 2 , the social level of the interlocutors seems to be roughly the same.

Situation 3: Imagine that a student has planned to meet you for a paper revision for a conference. You are a university professor, and you do not know the student. Due to an urgent meeting you miss the appointment. The next day you see the student in your office. What would you say to her?

Similar to the previous situations, the first type of strategy, namely, expression of regret was used more than other strategies by EFL learners. Male English native speakers used this strategy more than male EFL learners, while female English native speakers and EFL learners made use of this strategy in the same range. Another strategy which was used approximately at the same level of the first strategy, was explanation or account, which was used by English native speakers more than EFL learners. Male English native speakers, however, used this strategy more than female ones. Among EFL learners, females used this strategy more than males. Another strategy, explicit self-blame was not used by EFL learners, while English native female speakers used this strategy in 4 situations and male English native speakers used this strategy in just one situation. As the next strategy, Expression of embarrassment was used only in one 
situation by a female EFL learners. Similar to explanation or account, Offer of repair was also used more by English native speakers than EFL learners. Male English native speakers used this strategy more than others.

Situation 4: As a college student you were absent in two classes, and now you have forgot the medical statement as a reason. This was the first experience of your absence. Your professor who is teaching you for the first time, is a nice person. You are going to discuss the case. You are in her office now. What would you say?

Among English native speakers, Illocutionary force indicating devices (IFIDs) was used more than EFL learners, with males using this strategy more than females. Among EFL learners, female respondents used this strategy more than male ones. Expression of regret was used by Iranian female EFL learners more than English native speakers. In fact, this strategy was used by female EFL learners twice as much as English native female speakers, which may be due to the fact that this strategy is linguistically simpler than others. However, both male and female English native speakers, used this strategy in the same range. Another strategy used by the respondents more than other strategies was strategy number thirteen, offer of repair, which was used by English native speakers more than EFL learners. Male English native speakers made use of this strategy more than female English native speakers, while male EFL learners used this strategy only in fewer situations. Both male and female Iranian EFL learners applied offer of repair 5 times, however.

The next strategy was offer of apology which was used equally by English native speakers and EFL learners. By 7\% this strategy was used by English native male speakers and by $4 \%$ it was used by English native female speakers, while this strategy was used $9 \%$ by the female Iranian EFL learners and only by $2 \%$ by the male Iranian EFL learners.

Offer of apology was used by $9 \%$ by the female Iranian EFL learners and only by $2 \%$ by the male Iranian EFL learners. Surprisingly, the only participants who made use of the strategy of explicit self-blame were female Iranian EFL learners, who made use of this strategy in 6 situations. Request of forgiveness was the next class of strategies used in one case by male English native speakers, in one case by female English native speakers, by $2 \%$ by Iranian male EFL learners, and by $3.2 \%$ by female Iranian EFL learners.

Request of forgiveness was used by $2 \%$ by Iranian male EFL learners and by $3.2 \%$ by female Iranian EFL learners. As a case in this point, the phrase excuse me was used by the respondents. The last strategy used in response of this situation was promise of forbearance, which was used only by $2 \%$.

Situation 5: Imagine that you are a freshman and you are late. You hit another student's foot while running to class. You don't know this student. She says angrily "Hey, be careful!" What would you say?

Similar to most of other situations, the first class of apology strategies, namely expression of regret was used more than other situations. However, English native speakers made use of this strategy more than Iranian EFL learners, among whom male English native speakers used this strategy more than females. Similar to most of other situations, the first class of apology strategies, namely expression of regret, was used more than others. Among Iranian EFL learners, this strategy was roughly used equally by male and female participants ( $26 \%$ and $24 \%$, respectively). Offer of apology was used only by $4 \%$ by Iranian EFL learners ( $2 \%$ by males and $2 \%$ by females).

Situation 6: You are a freshman in college dormitory. You are watching a movie in your room when the student living in next room, knocks and says: 'Would you mind turning down the TV? I have an exam tomorrow and I can't concentrate.' What would you say?

In this situation, the trend continued and the first class of strategies, i.e. expression of regret, was used more than others. English native speakers made use of this strategy more than others, with male and female participants using this strategy roughly equally. Among EFL learners, female respondents used expression of regret more than males. Offering an apology was used just in one case, and that was by an English native speaker. Others did not report to use this class of apology in the mentioned situations. Similarly, request for forgiveness was used only once by a male EFL learner. Explanation or account was not used by the male participants at all; however, EFL learners and English native speakers used this strategy only once each. In the same vein, explicit self-blame was also used only by female EFL learners and English native speakers, three times by each, and it was not used by male participants at all. Offer of repair was also used by a low frequency by male and female respondents. In fact, the male English native speakers used this strategy by $4.5 \%$ and male EFL learners used this strategy by $3 \%$. The female English native speakers and EFL learners made use of this strategy by $7 \%$ each.

Situation 7: You have two kids and you along with some friends are invited to your friend's house for the first time. All the children are playing in the house when your younger son breaks an expensive vase. Your friend's wife says "Oh, no, this was a gift from my sister." What would you say?

In this situation, it is expected the strategy offering repair to be used with a higher frequency compared with other strategies as some financial loss has occurred and the person can offer a repayment. However, the obtained data of this situation showed that the first class of apology strategies, namely expression of regret, was again used more than other strategies. Surprisingly, even the English native male speakers chose this strategy more than female EFL learners the female English native speakers used this strategy more than others. Offering repair was the second highly used strategy which was used by English native speakers more than EFL learners, with male and female participants using this class of strategy equally. Female EFL participants chose this strategy more than male. Another strategies was offering apology, which was used equally by English native speakers and EFL learners, with male English native speakers choosing this item more than females. However, the story was vice versa with Iranian EFL learners and female EFL 
learners chose this strategy more than males. Explanation or account was also used by a low percentage by EFL respondents: $2 \%$ by males and $2 \%$ by females.

English native speakers, however, used this strategy more than EFL learners: three times by male and two times by female participants. Lack of intent and promise of forbearance were also used only once by English native female speakers and the other groups did not use these two strategies at all. In addition, only by 3\%, an English native male speaker, chose the strategy of refusal to acknowledge the guilt.

Situation 8: You and your friends are studying in the. There are some other students in the library and they are studying as well. The librarian tells you to be quiet in an angry tone of voice. What would you say?

Similar to the previous situations, expression of regret was used more than other strategies, and English native speakers made use of this strategy more than Iranian EFL learners (47\% cases compared with $20 \%$ cases). Females among English native speakers used this strategy more than male English native speakers.

Male and female EFL learners used expression of regret equally. Another class of strategies used by both EFL learners and English native speakers was the class of offer of repair, which was used with a frequency of $8(19.43 \%)$ by male English native speakers while the female English native speakers used this strategy just in 7\%. Male and female EFL learners used offer of repair with roughly the same frequency.

Request for forgiveness was the next class of apology strategies which was not used by English native speakers in response to this situation, while EFL learners used this strategy with a frequency of $7(18 \%)$. However, the next strategy was explanation or account which was not used by Iranian EFL learners while English native speakers used this class of strategy, though with a low frequency ( $5 \%$ by male and $5 \%$ cases by female respondents). The next class of strategy was explicit self-blame which only was used by female English native speakers, and other groups did not use this strategy. Admission of fact but not responsibility and concern for the hearer was used only in one case by female English native speakers. In addition, refusal to acknowledge guilt was used only by male English native speakers only in $7 \%$ of the situations. Offer of repair was used by na English native speaker more than EFL learners, with English native speakers using this strategy more than others.

Situation 9: Imagine that you have recently started a job, the other day you had a conflict with someone you didn't know, now you see he is your new boss. What would you say?

Similar to other situations, expression of regret was used more than other strategies by the respondents in response to this situation. However, English native speakers and Iranian EFL learners used this strategy equally (34\% compared with $32 \%$ ). Male English native speakers used this strategy more than others, though. In addition, male EFL learners used this strategy more than female ones. Besides, Male EFL learners used expression of regret more than female ones.

Offer of apology was used by English native speakers twice as many times as it was used by EFL learners. Female English native speakers used this strategy more than others. This strategy was used by English native and male EFL learners equally (7\%). Explicit self-blame was also used by male English native learners and EFL learners only by $2 \%$. Female English native speakers used this strategy more than other strategies. Lack of intent was used only once by female English native speakers and the others did not use this strategy. Admission of fact but not responsibility was the next class of apology strategies which was used by English native speakers and male EFL leaners equally ( $7.6 \%$ by each); however, female English native speakers used this item only in one situation and female EFL learners did not use this strategy at all. Female English native speakers were also the only group who made use of the strategy of concern for the hearer with a frequency of $3(6.7 \%)$. Offer of repair was also used by English native speakers and males Iranian EFL learners equally. By $8.4 \%$ the English native females made use of this strategy, which females Iranian EFL learners made no use of. Surprisingly, the strategy of promise of forbearance was used by all groups of respondents only once. A Chi-square test was run between different classes of apology strategies used by English native speakers and EFL learners. The results are presented in Table 4.

Table 4. The Results of Chi-Square Test between English Native Speakers and EFL Learners in Their Apology Strategies

\begin{tabular}{llcl}
\hline & Value & df & $\begin{array}{l}\text { Asymp. Sig. (2- } \\
\text { sided) }\end{array}$ \\
\hline Pearson Chi-Square & $20.533 \mathrm{a}$ & 17 & .248 \\
Likelihood Ratio & 28.267 & 17 & .042 \\
N of Valid Cases & 28 & & \\
\hline
\end{tabular}

According to the statistics presented in Table $4, \chi(17)=20.53, p=.248$. This tells us that there is no statistically significant difference between EFL learners and English native speakers in terms of their usage of apology strategies. 


\section{Discussion and Conclusion}

The results of the present research showed that the apology strategies proposed by Cohen and Olshtain (1981) were used by English native speakers except two of them, namely, expression of self-deficiency, and expression of embarrassment. Among the other strategies expression of regret, like 'I'm so sorry' and offer of repair, e.g. 'I'll change it by a new one.' in addition to explanation or account, e.g. 'I had a puncture.' were employed by the English native speakers more than other strategies. Offer of apology, e.g. I do apologize, and request for forgiveness, e.g. pardon me' scored the next. Explicit self-blame, e.g. I made mistake', and lack of intent, e.g. I was unintentional' were the next classes of apology strategies used by English native speakers to the DCTs. The other strategies were used with a percentage of less than one percent. In addition the results of comparison between English native speakers and Iranian EFL learners revealed no statistically significant difference between the two groups in spite of some similarities and differences between the two groups.

This study tried to contribute to the existing literature on cross-linguistic speech act research by examining the sociolinguistic differences in the performance of apology strategies between Persian EFL learners and American speakers. As far as the results of this study in terms of the quantity of apology strategies are concerned, the results support the study by Olshtain (1989). According to Olshtain (1989), strategy one (IFIDs, under which expressing regret, offering apology and requesting for forgiveness are categorized) is a general category, i.e. the three items of this category can be used across all situations that require an explicit act of apology. The three groups of this class demonstrate the offender's willingness to express an apology for a violation explicitly. This supports the idea presented above about the preference for minimizing or denying responsibility. However, the analysis of the data also showed that the respondents not only tried to save their own face in their apologies, but were also concerned with maintaining the friendship with the hearer, sometimes even explicitly mentioning that their friendship was more important than the action that triggered the apology.

IFIDs are characterized as formulaic, routinized and conventionalized forms of apology containing the performative or apology verbs (Olshtain, 1989). In fact, IFIDs are the most direct realization of an apology. However, contrary to the findings of the present study, category three was not used by English native speakers as Olshtain (1989) expected. Olshtain (1989) believed that the third category of Cohen and Olshtain's (1981) classification is a general category and is commonly used everywhere. However, in the present study, it was found that not many English native speakers made use of this category.

In order to answer the second research question, the results obtained English native speakers and Iranian EFL learners were compared. The results of the comparison of the apology strategies used by English native speakers and Iranian EFL learners' analysis showed that although there were some similarities and differences between these two groups, the difference between them was not statistically significant.

According to Shariati and Chamani (2010), "the range of apology strategies which are used in Persian closely resemble those used in languages studied in the CCSARP project" (p. 1693). However, because of the different sociocultural values that govern language use, preferences in the use of apology strategies vary across languages. Shariati and Chamani refer to four types of IFID in their data, of which three fit into the subcategories specified by Cohen and Olshtain (1981). According to Shariati and Chamani, šærmændæm, an expression of shame, is specific to Persian. In their corpus, requesting forgiveness, bebaxšid, is the most frequent IFID, and an expression of regret, mote'asefam, is the least frequent IFID. Moreover, the most frequent combination of apology strategies in Persian includes an IFID (request for forgiveness) with an acknowledgment of responsibility. Shariati and Chamani also claim that apologies in Persian can be used to show sympathy and condolence, but this usage was not considered in the present research.

One implication concerns English as a foreign language (EFL) teaching: EFL teachers should be aware that fluency in the English language does not involve only linguistic knowledge but also sociocultural knowledge. Hence, comparing the similarities and differences in apologies of L1 and L2 may be one pedagogical way to raise learners' linguistics and pragmatics awareness in EFL learning. The findings of the present study also confirm the importance of teaching pragmatic competence, and specifically teaching apology strategies in the language classroom.

Exercises in textbooks should be based on samples of authentic materials or specially written conversations which show the conversational routines and strategies used in the realization of an apology act. They should not focus simply on one semantic formula as in "sorry", "I'm sorry" or "I'm very sorry." Tasks in textbooks should have activities such as roleplays to give learners better experience of speaking English in a specific situation. Iranian EFL learners who are surrounded by their native language (Persian) and culture and rarely have the opportunity to use L2 (English) outside of the classroom, need to be given as many opportunities as possible to practice their communicative competence in the language classroom.

Even though there is some discussion about the relationship between sociocultural norms and the choice of strategies in the case of some of the situations presented in this study, a more in-depth analysis of this issue is needed to be done in a future study that will compare the way apologies are conducted across speakers of other languages. Consequently, further study is needed before any generalization can be made. The first possible direction could be the broadening of both the age range of the respondents, and their social background, which would lead to a better understanding of how social and demographic factors influence the choice of apology strategies. 


\section{References}

Al Ali, S. A. S. (2012). A cross-cultural study of the speech act of apology by Saudi and Australian females. Unpublished master's thesis, University of Melbourne, Australia

Austin, J. L. (1962). How to do things with words. Oxford University Press, Oxford, England.

Cohen, A. D., \& Olshtain, E. (1981). Developing a measure of sociocultural competence: The case of apology. Language Learning, 31(1), 113-134.

Blum-Kulka, S., \& Olshtain, E. (1980). Requests and Apologies: A Cross-Cultural Study of Speech Act Realization Patterns(CCSARP). Applied Linguistics, 5(3), 196-213.

Eslami-Rasekh, A., \& Mardani, M. (2010). Investigating the effects of teaching apology speech act, with a focus on intensifying strategies, on pragmatic development of EFL learners: The Iranian context. The International Journal of Language Society and Culture, 30(1), 96-103.

Farashaiyan, A., \& Amirkhiz, S. (2011). A descriptive-comparative analysis of apology strategies: The case of Iranian EFL and Malaysian ESL university students. English Language Teaching, 4(1), 224-236.

Nasiri, S. R., \& Forutan, A. (2015). On the Iranian EFL Teachers Apology Production. Procedia-Social and Behavioral Sciences, 110, 1987-1997.

Olshtain, E. (1989). Apologies across languages. Cross-Cultural Pragmatics: Requests and Apologies, 155173.

Parsa, H. (2012). Apology strategies of Iranian ESL students. Unpublished Master's Dissertation. University of Malaya, Malaysia.

Rizk, S. (2003). Why say “NO!” when you refuse. Journal of the Faculty of Education. 3, 1-27.

Salehi, R. (2014). A comparative analysis of apology strategy: Iranian EFL learners and native English speakers. Procedia-Social and Behavioral Sciences, 98, 1658-1665.

Saville-Troike, M. (1982). The Ethnography of Communication: An Introduction. Blackwell. Retrieved from https://books.google.com/books?id=HbFhAAAAMAAJ

Savina, E. (2002). The influence of American English on Russian apologies. Studies in Second Language Acquisition, 27(3), 78-89.

Shariati, M., \& Chamani, F. (2010). Apology strategies in Persian. Journal of Pragmatics, 42(6), 1689-1699.

Simin, S., Eslami, Z. R., Eslami-Rasekh, A., \& Ketabi, S. (2014). The effect of explicit teaching of apologies on Persian EFL learners' performance: When e-communication helps. International Journal of Research Studies in Language Learning, 3(4). 